\title{
LANTICA PIZZERIA DA MICHELE AS A CASE STUDY OF TRADITIONAL SPECIALITY GUARANTEED AND INTERNATIONAL FRANCHISING
}

\author{
Andrea Gatto ${ }^{1}$ \\ ${ }^{1}$ Corresponding author. Natural Resources Institute, Greenwich University, Central Avenue, Chatham Mari- \\ time, ME4 4TB, UK" to "Natural Resources Institute, University of Greenwich, Central Avenue, Chatham \\ Maritime ME4 4TB, UK.
}

1a.gatto@greenwich.ac.uk.

\begin{abstract}
This work explores the case study of L'Antica Pizzeria da Michele as a best practice of traditional speciality guaranteed and international franchising. Besides being one of the most ancient and successful pizzerias in Naples, da Michele is renowned all over the world for the quality of its raw products, dough processing, and output. In the last years, da Michele also started pioneering the pizza production and commerce industry with an innovative franchising model and a new company appointed to managing this latter business. This work makes use of in-depth interviews and data collected on the field. For such scope, top managers and employees of both the local and the international companies were interviewed. The study finds that da Michele managed to become a benchmark for territorial food products and, more recently, for high-standard franchising, jumpstarting a successful brand-new company and food business project.
\end{abstract}

Keywords: traditional speciality guaranteed, franchising, in-depth interviews, labelling, food business, da Michele, Neapolitan pizza

(JEL Classification: $O 13, Q 13, Q 16, Q 17$ )

\section{INTRODUCTION}

\section{Pizza in the history of Naples}

Neapolitan pizza is one of the most renowned and sold foods in the world. The business of pizza in 2017 reached 134 billion dollars in terms of worldwide pizza market (Euromonitor, 2017). Pizza can also be classified as one of the most ancient street foods ever, having been sold in the streets of Naples since the XVI century, although its origins are praised for being even more ancient (Helstosky, 2008). Evidence comes from the fact that most ancient pizzas were sold from vendors roaming around the city and carrying heavy containers for preserving the product heat (Niceforo, 2019). Lately, proper bakeries producing pizza spread all over the city. These populated Naples in the XVIII and the beginning of the XIX century but were usually not provided of dining rooms: these earliest pizzerias resembled more bakeries than restaurants, working for the sole take-out of products (Mattozzi, 2015). The pizza bakeries used to prepare and sell pizzas to be eaten standing-up, on outdoor, high, wooden supports, as it was typical for other foods as pasta (Serao, 2016).

Pasta was another popular food that was widely sold in the streets of Naples, shaping another ancient street food and a distinct food trade job - maccarunari (Basile, 2019). Cohorts of lazzaroni and poor, as described by Alexandre Dumas, were struggling to avidly eat their scorching pizzas (Dumas, 1843). An entire pizza was usually not affordable from the people - the amount of purchased pizza varied, instead, depending on the customer's budget (Helstosky, 2008). Only lately, basic tables, benches, and chair were introduced, and 
first pizzerias - as we know them - were established and spread all over Naples. The pizza toppings used were basic, and the final product was a humble food that varied according to the season and the harvests.

Today as centuries ago, pizza is a simple, genuine dish, rooted in the Neapolitan and Italian diet. Even if it is often packed with calories, its products are deemed to be healthy and nutritionally important - with some variations, pizza could even become a balanced food. Besides reaching the tastes of the vast majority of consumers since centuries, pizza also meets new food exigencies and trends, including intolerances, allergies, vegetarian, and vegan diets - and most of the pizzerias are equipped to offer varieties and variations that meet modern dietary requirements.

\section{Neapolitan pizza and its imitations: tutelage and labelling}

The international and domestic success experienced by the Neapolitan pizza started from the second half of the XX century. This fact led to a divulgation of pizza as international food, but the drawback was that the original product started suffering from many attempts of imitation. Throughout the years, new types of pizzas in the world multiplied foods that nowadays claim their own identities. Some examples are New York-style pizza, Chicago pizza, California pizza, and even Roman pizza. On one hand, this must be welcome as a sign of the times and of the greatness of the product (Sanchez, 2008). On one other hand, it must be noted a scaring fact connected with traditional foods, culture, and identity preservation, both as a social and artistic case, and in terms of profits.

More than being traditional, typical, or variations of pizza, these products - even when of good quality - are not assimilable with the food characteristics of the Neapolitan pizza and what is and has been associated with pizza, configuring as different products in the best case. This is also confirmed from the traditional speciality guaranteed (TSG) protocol, that requires to use a limited range of ingredients and only two types of pizzas - margherita and marinara (EC, 2010). With the objective of preserving its value and tradition, the Neapolitan pizza has been recognised by several labels and certificates that aim at preserving its tutelage. In terms of labelling, the Neapolitan pizza is one of the two registered traditional speciality guaranteed (TSG) from the European Union - along with mozzarella di bufala campana (EC, 2010). Nationally, Neapolitan pizza is recognized as one of the core traditional agri-food products (PAT) from the Italian Ministry of Agricultural, Food and Forestry Policies (MIPAAF 2015). Another effect is that often, when the quality of the products is scant, the imitations damage the reputation of the original product, besides subtracting income from the original product.

\section{Pizza in the international markets and franchising}

Food business and agribusiness are prior industries to be enhanced for market boosting (Drago \& Gatto, 2018). These industries are a central element of the Italian economy and society, pervading the Italian culture and habits (Briganti \&
Gatto, 2015). The international dimension is nowadays often a requirement for keeping business profitable. In the US, as in many overseas markets, a big discrimen exist between local pizzerias (having a limited number of branches) and chains. The formers are usually less profitable, less stable, less updated and innovative, and more vulnerable to crises and thus to failure with respect to the latters (Technomic, 2017; CHD, 2017). The market is mainly dominated by a few massive chains, retaining market power. Often, both local pizzerias and, above all, big chains, opt for franchising, being one of the most used and less risky business strategy and legal form for expanding locally or internationally a food business.

Many food franchising have been spreading out in several countries in the last decades, and the pizza industry is not exempt. Franchising is not an alien principle for small business economics and development; some of these businesses were successful in putting forward franchising as a development strategy, holding the small sizes of both the franchisees and the franchisor (Stanworth et al., 2004). Innovative models recalling sustainable business are a fundamental element of firm success, especially in start-ups and sectors related to natural and behavioural aspect - as for food and pizza industries (Franceschelli et al., 2018). This is confirmed from the fact that, nowadays, food and nutritional sustainability is notably considered a policy prior (Agovino et al., 2018), along with agricultural and rural aspects, calling for development action (Gatto et al., 2016).

This work uses the following structure: this section introduced the business and commercial relevance of pizza in the international and local food industry, emphasising the uniqueness and authenticity of the Neapolitan pizza as a product - verace pizza napolitana. Here is also explored the role of labelling and the phenomenon of franchising in an international breadth. The next section explores the methodology adopted for conducting the research - namely the in-depth interviews obtained in the field. Following, results are commented along with a discussion session. On one hand, it is stressed the importance of certificates obtained by da Michele's suppliers in guaranteeing the high quality of raw products. On the other hand, it is examined the success of the internationalisation policies, that in the last years allowed da Michele to launch high-standard franchising all over the world.

\section{MATERIALS AND METHODS}

\section{Data and methods used}

This work uses qualitative research methods to obtain new data for analysing a good practice of the Italian food industry. With the objective of analysing a case study, selected interviews with key staff of both da Michele and da Michele in the world were conducted. The in-depth interviews were realised to explore the main historical facts, the managerial policies, and understand the overall socio-cultural and exogenous factors that determined the company achievements and figures at both the local and international levels. 
Besides the scopes of understanding the companies business drivers, the in-depth interviews were also realised to generate and present new data on these issues. For these scopes, staff from da Michele and da Michele in the world were detected as target and therefore interviewed. Open-ended questions were conducted. All of the interviews were realised vis-à-vis. Data were collected on-site and eventually cleaned and electronically processed; it was first confirmed the validity and coherence of data, that were then arranged and organised according to specific topics categorisations. Thus, information was clustered, analysed, and interpreted. The main outcomes were synthesised, sketched, and presented.

The interviewees' panel included top managers and specialists from the two companies - especially from marketing and internationalisation departments -, pizzaioli, bakers, and further workers. The interviews took place in da Michele and da Michele in the world headquarters, in the historical branch of Naples, and in further selected places. Being a small, (quasi-)family-run business, for confidentiality reasons, the identity and appointments of people involved in the study will not be disclosed.

\section{RESULTS AND DISCUSSION}

\section{L'Antica Pizzeria da Michele: a history of a traditional product}

The origin of L'Antica Pizzeria da Michele is intertwined with the history of Naples, through 150 years of changes and millions of pizzas baked, which have contributed making Neapolitan pizza one of the most recognisable and exported food in the world. The Antica Pizzeria got a long history: born in 1870, Condurro family, led by the founder Salvatore, was one of the first pizzerias in the historical centre of Naples. Salvatore jumpstarted the first business in 1844 when he served Nicholas I, Zar of Russia, inventing for the occasion the "cosacca" pizza. Salvatore also became an adjunct pizzaiolo at the Court of the Bourbons during the Kingdom of the Two Sicilies.

Salvatore's son, Michele Condurro, perfected his technique by combining the wisdom of tradition with the secrets of Torre Annunziata masters, an old, reputed school in the pizzabaking dough processing. Learning the craft, Michele opened the first pizzeria in 1906 and moved to the current location in 1930. Michele had the great intuition of believing in the mission and vision that have allowed the corporate success notably the quality and simplicity of local products and the technique of dough processing.

Da Michele is worldwide famous for preparing only two simple types of pizzas: Margherita - made of tomato sauce, fiordilatte, extra-virgin olive oil, basil, and pecorino cheese, and served as normal, medium, or double mozzarella - and Marinara - made of tomato sauce, oregano, garlic, and extravirgin olive oil, and served in normal, medium, or maxi size. This way, Antica Pizzeria aims at preserving the ancient procedures and techniques that qualified da Michele as a best practice.
Da Michele's pizza has gone through all these years keeping intact the secret of the dough that gives the two pizzas produced lightness, high digestibility, and an unmistakable taste, due to the combination of the ingredients, the dough maturity and leavening. The number of customers generates itself a small business for tourism and the local economy. The success of the Antica Pizzeria must be attributed to various factors: above all, the will to preserve the ancient flavours of the tradition of Neapolitan pizza makers, and the result of a mixture of ancient crafts and a cautious openness to the innovations brought by the global integration of the markets.

At the basis of the good output, two factors emerge: the products quality and the mastery skills. Pizza has humble origins and traditionally uses simple products: water, flour, salt, tomato, cheese, and oil. Therefore, it is fundamental to ensure the quality and origin of the products and controlled processing. Most of the success of da Michele is due to the pizza makers skills. It is not a surprise the fact that, on December 4-9, 2017, UNESCO inscribed the art of the Neapolitan pizza maker, pizzaiuolo, on the Representative List of the Intangible Cultural Heritage of Humanity (UNESCO, 2017).

\section{Da Michele's suppliers and their certifications}

Da Michele's suppliers achieved important certifications, that confirm the quality of the raw materials. The dough is prepared in the old laboratories of Via Cesare Sersale 1/3, where over the years the right balance of temperature and humidity, essential for obtaining optimal leavening, has been perfected. The preparation starts from the Antico Molino Caputo flour, red quality in the warm months and blue quality in the cold months; the flour is mixed with water, mother yeast - criscito -, and small amounts of brewer's yeast, which dosage is pondered depending on the season. The dough is prepared manually with the aid of a mixing machine that amalgamates the ingredients. The sorting dough is homogeneous, lumpsfree, ready to be divided into small pieces of 250 - medium - or 300 grams - maxi. The pieces are rolled - arrotati wide to preserve the softness of the dough and left to rise. Da Michele kept a slow leavening, following the old recipe indication to let the dough to rest twenty-four hours to make it reach the maximum leavening. This step is fundamental to guarantee lightness and high digestibility. Depending on the season, the preparation undergoes small variations. Caputo has been operating in Campania since 1924, and in San Giovanni a Teduccio since 1939, using slow grinding and avoiding additives. The basic wheat is Italian, coming mostly from Central Italy (especially Marche and Umbria). Once the grinding is finished, the product is mixed with wheat from Central-Northern Europe. The soft wheat flour "00" Caputo was designed as one the ingredients for pizza as a Guaranteed Traditional Speciality (STG), a certification promoted by Associazione Verace Pizza and Associazione Pizzaiuoli Napoletani, certified by Is.Me.Cert (EC, 2010).

Da Michele's tomato is a San Marzano prepared and stored by Solea, a company operating in agro nocerino-sarnese, 
using tomatoes from Campania, Puglia, and Emilia Romagna. The puree used for pizza is made of the homogenized peeled tomato. Solea obtained the ISO 9001 Quality Certification for stringent checks regarding raw materials, processing, and canning, that assures quality, genuineness, hygiene and safety. In 2011 Solea obtained the Global Standard for Food Safety certification from BRC and UKAS.

The fresh cheese used for Margherita is fiordilatte. This cheese is preferred to the alternatives - provola and mozzarella -, being its consistency more compact and less watery; fiordilatte ensures a dry and well-baked pizza, fundamental for taste and presentation. The brand is Fior d'Agerola, produced by Fusco Brothers. Fior d'Agerola is a gastronomic excellence of the Monti Lattari (Sorrento Peninsula), that attributes to the pizza a distinct and recognisable flavour. Fusco has been working in Agerola since 1840, producing mostly fiordilatte PAT. Fiordilatte is obtained with raw whole cow's milk coming from several milking, made in a maximum of sixteen hours, freshly delivered for processing, and produced with a portion of milk from the Agerola cow that makes it particularly tasty.

The choice of oil is notably widely debated. The recipe of the Antica Pizzeria foresees the use of seeds oil in reason of its lower body compared to olive oils: in da Michele's pizza, the oil has the role of seasoning and accompanying the other ingredients without covering them, leaving space to the taste of fiordilatte and dough. Moreover, the seeds oil is considered more suitable for the high temperatures of the wood oven (almost $400^{\circ} \mathrm{C}$ ). Antica Pizzeria chose another quality brand, Masturzo, established in Naples in 1913 and working in Campania since 1870 . The firm achieved quality certifications such as: IFS standards, BRC Global Standard for Food Safety, and UNI EN ISO 9001. The cheese used to garnish da Michele's pizzas and bind the flavours is the pecorino romano IGP, preferred to parmigiano reggiano for its less invasive flavour and greater salinity, which allows to not add salt on the finished product, that would alter the final flavour. Basil, oregano, salt, and garlic are added to the main ingredients.

\section{Da Michele in the world srl: ingredients for an international franchising success}

Condurro family business reached its fifth generation, composing a team of pizza makers and bakers, managers, consultants, and experts. The international expansion of the business starts in 2012 with L'Antica Pizzeria da Michele in the World srl (Condurro, 2017). The new company was conceived to create a limited quantity of pizzerias in the world, in strategic places showing demand, robust commercial proposals, and the willingness to spread the culture of verace pizza napolitana throughout training and strict periodical checks. Thanks to modern production systems, ICT, trade, and transportation technologies, the great-grandchildren of Michele have developed a production system that recreates the historic Neapolitan workshops in different corners of the world, to use the same ingredients, and to produce the same dough. Despite numerous proposals for commercial affiliations, Condurro family has always been cautious in embarking commercial expansions, to protect the family brand and keep the trust of millions of customers. Numerous environmental factors increase the difficulty to reproduce the same blend out of Naples: temperature and humidity of the laboratories, water properties, logistical and regulatory reasons for food shipping. The risk was to create a chain of pizzerias sharing uniquely the name, serving products qualitatively different, with no standards.

The historic headquarters remain the only branch in Naples despite numerous imitation attempts. Japan has been the first country where the company jumpstarted the project in 2012, following a consolidated tradition of high standard customers, pizza makers, and product, due also to the phenomenon of Neapolitan pizzaiuoli migration (Ceccarini, 2010). In Japan, da Michele has implanted stably in Tokyo (since 2012) and Fukuoka (2015), whereas a Yokohama branch opened in October 2019. Other branches established in Europe were located in London - Baker Street (2017) and the new unit of Soho (2019) -, and Barcelona (2017). More recently, the franchise enlarged in the United States - Los Angeles, in Hollywood (2019) - , and the United Arab Emirates - Dubai (2019). In Stockholm, it was jumpstarted the first international firm consulting project in 2017. Some new branches were opened in Italy too: in Rome - two branches (2016 and 2018) -, Milan (2017), Florence (2018), Verona, and recently in Bologna (both in 2019).

The essential phases of the start-up are designed as:

- the apprenticeship of the new employees at the mother company;

- a strict application of the quality manual, followed by periodical quality checks;

- monitoring healthiness and financial and structural growth from the start-up phase to business consolidation.

Franchisees are required to use the same raw materials utilized in Naples, shipped fresh all over the world by plane or ferry. Further directive strategies have been developed to internationalise the project, especially in marketing: the brand registration, a new logo, merchandising and commercial campaign by the mother company and the franchises; constant directive exchanges and stakeholders' meetings.

In order to better meet local customers' satisfaction, the franchisees - both the foreign and the Italian - are allowed to propose to the mother company slight variations in the menus with respect to the Neapolitan one. This is the case of some enlargement in the pizza choice - that include the addition of some other pizzas from the Neapolitan tradition - and in the sides and drinks - where some traditional Neapolitan food and beverages were included. For this scope, and to ensure highquality standards, some partnerships have been signed with targeted brands, commercialising finished products - from coffee and pastry-making to mineral water, beer, and wine; these partnerships complete the existing agreements on the use of raw products - as for wheat, tomatoes, fiordilatte, and extra-virgin olive oil.

Franchisees are also required to stick to a minimum of four-years contract and can benefit from the exclusivity in 
the area, that allow them to be the only brand restaurant in the business zone. Entrance fees and royalties vary according to the country, the area, and the negotiation. The franchising must meet the requirements of being implanted in commercially relevant areas of minimum 15000 inhabitants; its size should be no less than 300 square metres, whilst the personnel number can vary.

Da Michele in the world developed the strategy of providing the following professional benefits to its franchisees:

- start-upping support, paramount from the first months to the second operative year;

- training and know-how transfer, ensured by experienced executives, pizzaioli, and bakers;

- quality checks and technical consulting, to ensure the high standards of quality and a rigorous similarity amongst the products coming from the different branches and countries and technical support;

- customer service, held by the mother company;

- events, to push the franchising, the brands, and the name of da Michele, building new synergies in Italy and abroad.

\section{Discussion: an appraisal of international franchising and business models for the pizza industry}

Business models amongst pizza chains and smaller, traditional franchising as da Michele, considerably vary. One of the main differences lays in the fact that in the big chains takeaway or delivery is often the core - or even the unique - business target and the main source of income. This is also due to the productive model, where these businesses propose pre-assembled/pre-prepared pizzas to be warmed up/de-frozen, to be quickly taken away in a few minutes. Finally, the size and characteristics of these businesses define them as proper chains. Instead, da Michele proposes a small, increasing number of franchising, where the mother company is able to monitor and know all the businesses. Also, it proposes restaurants instead of deliveries and take-away shops. The target is also different, being foodies instead of people that simply want to get quick food. Prices may also vary, but this depends on the place of delivery. Da Michele proposes a specific product: to provide the real Neapolitan pizza experience to its customers in the world as if they were in the centre of Naples.

As compared to most renowned pizza franchising, da Michele has diverging objectives, figures, targets, strategies and managerial models. Last but not least, big chains and the case study produce totally different products, that only share the same name - arguably. Most of these franchising are American - hardly Neapolitan or even Italian -, although often Italian sounding is easily detectable in their names and products. Often, the range of products from these chains is decisively broader with respect to da Michele, serving dozens of varieties of pizzas - including unusual or exotic genres -, but also sandwiches, kebabs, pasta, deep-fried foods, and other dishes not even remotely associable with products served in Neapolitan pizzerias. Most of the pizza franchising are chains, counting on thousands of franchisees in hundreds of countries, hundreds of thousands of employees, billion-dollars revenue, and are even quoted in the stock exchange.

This is the case of Domino's Pizza, that declared reaching over 1,7 billion dollars revenue per year, having around 150000 employees spread over 12000 franchisees in more than 80 countries. If it is true that the sector comes from a traditional product, Domino's has found the necessity to reinvigorate its business by promoting a "radical, deep-seated change in a traditional, slow-to-change business" employing a vast amount of employees and resources in software and analytics (Taylor, 2016). This business targeted improving its brand, including the change in the name from Domino's Pizza to Domino's. Though more remarkable recent business innovations for Domino's pointed at providing better IT and delivery solutions, more fungible options for its customers. These strategies lead to different business models, but also different missions.

Further major pizza chains that internationalised their businesses with franchising are notably Pizza Hut and Papa John's Pizza. The first is the world leader when it comes to the number of countries covered (more than 110) and locations (more than 18000). Pizza Hut implemented both the delivery and the restaurants. It diversified its product, producing a vast variety of pizzas, also in terms of cooking, including the Italian-style typology. However, differences in franchising and overall business models with respect to our case study should arise clearly. As remarked previously in the literature: "Pizza Hut played a major role in turning pizza from an Italian speciality into a mass-market, mainstream food." (Mike \& Slocum, 2003). Nevertheless, also Pizza Hut has passed through deep revisions of the company culture, that include brand values, re-branding, HR changes, overall updates, and effectiveness measurement policy. Papa John's Pizza as well got both delivery and restaurants. It diverges from our case study in many regards, including the core target of delivery, the final product, the size, and the target.

There exist as well Italian franchising cases, such as Rossopomodoro or Fratelli La Bufala. However, the units of these companies considerably vary amongst each other in terms of business models, objectives, and identity. If da Michele aims at providing a homogeneous, high-quality standard, the former businesses display a broad variety of both characteristics and quality from branch to branch. This is because these pizzerias were conceived for franchising from their very first years of operation, having in their agendas the purpose of implementing food business chains. This fact is confirmed from the personal data: they are all recently born. Another difference between these companies and da Michele concern the size - notably smaller for da Michele -, and the exclusivity of the Neapolitan branch - not respected from the other businesses. What is mostly resembling the business model of da Michele are other renowned, traditional, highquality pizzerias, that are opening branches in other cities in Naples or abroad. Though, in most cases, these did not opt for franchising, managing directly the new branches.

\section{CONCLUSIONS AND PROSPECTS}


Preparing traditional Neapolitan pizza is considered an art and is due to a complex mix of factors: respecting a strict set of rules, observing the indicated ingredients list, methodologies and techniques, equipment used, and characteristics of the final product that are strictly regulated (EC, 2010). For instance, wooden hoven is a requirement for a Neapolitan pizza TSG, and many businesses out of Naples lack this fundamental element. Improper use of the names and the labels lead to detrimental economic and reputation effects for the authentic product and brand.

This research aimed at proposing business models alternative to the leading pizza franchising. The final objective of the case study examined, da Michele, is challenging and enthralling: differently from other pizza and food/restaurant franchising, da Michele aims at keeping high qualitative standards and close similarity to the final output of their products being them implanted in Naples, Italy, Europe, or worldwide. This is due to the application of rigorous rules, controls, and the use of best-quality, local raw products. Intuitively, over 150 years of know-how of pizza baking is a further relevant added value, to be coupled with a new managerial imprint. These factors, typical of a pioneering practice of traditional food franchise, should be able also to solve the franchisor-franchisee divide in terms of learning capacity and experience, typical of food and pizza franchise (Kalnins \& Mayers, 2004). In these regards, size and ancient knowledge can be strong drivers of success.

The strategy of combining high-quality standards and franchising might be less straightforward in the start-upping phase of the new branches but the model will be more likely to ensure a long-lasting business success to both the branches and the mother company. Besides targeting a different market segment, this is mainly attributable to the fact that both expatriates and local people all over the world are increasingly raising the bar when it comes to food quality requirements, refining their tastes toward more qualitative, finer food. Successful pizzerias and restaurant, especially when dealing with an international franchise, will have to consider and analyse this trend, targeting their future business policies toward this goal. This fact should also relate to the evidence that pizza consumption is affected by socio-demographic characteristics, qualitative attributes of pizza, and subjective beliefs (Di Vita et al., 2016).

There is another important factor in favour of human touch and qualitative internationalisation of traditional food business: technological innovation is changing the way food is consumed, improving the delivering service, supplying new food experiences, and paving the way for new markets. Though informatisation by now still relies on on - and will be likely to rely for many upcoming years - on the human component, it is connected with deliveries, IT services, or further functions. For the food industry, space is still a thing. Therefore, spatial economics and regional development dynamics will still favour the traditional food industry with respect to technological innovation for many years (Couclelis, 2004). Another central discriminant penalising the quality of pizzas delivered comes again from the TSG protocol, that prescribes that pizza must be consumed in the place where is baked (EC, 2010). These implications leave room for new business and scholarly explorations in the field.

The first results and the long-term goals of da Michele are encouraging for the family firm and the model defended and envisage the possibility of creating economic and social value both for the company and for the local areas where the pizzerias are being opened. Above all, the application of the qualitative standards and the managerial processes of the franchising implemented will ensure income and outlets to the mother company, contributing to the local development of Naples and the affirmation of the authentic, traditional Neapolitan pizza.

Concluding, the entrepreneurial project of da Michele in the world aims at creating a long-lasting business, as well as economic and social value for the territory, throughout the valorisation and export of a proud cultural, socio-economic, and culinary tradition proper of the Neapolitan identity - pizza and the art of baking it. The goal is to preserve the quality of the historic craft, opening to innovation. The remaining ingredients of the secret recipe are know-how, hard-work, quality, and dedication for mastery and a profession carried out with passion over 150 years, never forgetting own identity and a popularly recognised tradition.

\section{ACKNOWLEDGEMENTS}

The author wishes to thank L'Antica Pizzeria da Michele in the World srl and its general manager Alessandro Condurro for releasing the in-depth interviews that were used for this paper. The author acknowledges the referees and the editors for their valuable comments and encouragements that improved the paper.

\section{REFERENCES}

Agovino, M., Cerciello, M., \& Gatto, A. (2018). Policy efficiency in the field of food sustainability. The adjusted food agriculture and nutrition index. Journal of environmental management, 218, 220-233.

Basile, G. (2019). From maccaronaro to street food: a cultural and linguistic study. The wor (1) ds of neapolitan arts and crafts: cultural and linguistic perspectives, 12 .

Briganti, R., \& Gatto, A. (2015). Agribusiness e alimentazione: prospettive per il lavoro e lo sviluppo economico nel mondo. Futuri, 5.

Ceccarini, R. (2010). Food workers as individual agents of culinary globalization: Pizza and pizzaioli in Japan. Food and Culture: A Reader, 437-448.

\section{CHD Expert (2017). US Pizza restaurant data.}

Condurro L. (2017). L'Antica Pizzeria da Michele. Dal 1870 la pizza di Napoli. 
Couclelis, H. (2004). Pizza over the Internet: e-commerce, the fragmentation of activity and the tyranny of the region. Entrepreneurship \& Regional Development, 16(1), 41-54.

Di Vita, G., Pappalardo, G., \& D’amico, M. (2016). Exploring The Determinants of Consumption For An Italian Traditional Product: The Case of Pizza. Quality-Access To Success, 17.

Drago, C., \& Gatto, A. (2018, March). A Robust Approach to Composite Indicators Exploiting Interval Data: The Interval-Valued Global Gender Gap Index (IGGGI). In IPAZIA Workshop on Gender Issues (pp. 103-114). Springer, Cham.

Dumas, A., Temple, W., \& Whyte, J. D. (1843). Le corricolo. Dolin, Libraire-Commissionnaire, Quai des Augustins, 47.

Gatto, A., \& Drago, C. (2020). A taxonomy of energy resilience. Energy Policy, 136, 111007.

Gatto, A., \& Drago, C. (2020). Measuring and modeling energy resilience. Ecological Economics. DOI:10.1016/j. ecolecon.2019.106527

Gatto, A., \& Busato, F. (2020). Energy vulnerability around the world: The global energy vulnerability index (GEVI). Journal of Cleaner Production, 118691.

Gatto, A. (2020). A pluralistic approach to economic and business sustainability: A critical meta-synthesis of foundations, metrics and evidences of human and local development. Corporate Social Responsibility and Environmental Management. DOI:10.1002/csr.1912

European Commission (2010). Regulation No 97/2010 of 4 February 2010 entering a name in the register of traditional specialities guaranteed [Pizza Napoletana (TSG)].

EU (2014). Commission Implementing Regulation No 668/2014 of 13 June 2014 laying down rules for the application of Regulation (EU) No 1151/2012 of the European Parliament and of the Council on quality schemes for agricultural products and foodstuffs.

Euromonitor (2017). Trends in consumer foodservice.

Franceschelli, M. V., Santoro, G., \& Candelo, E. (2018). Business model innovation for sustainability: a food startup case study. British Food Journal, 120(10), 2483-2494.

Gatto, A., Polselli, N., \& Bloom, G. (2016). Empowering gender equality through rural development: Rural markets and micro-finance in Kyrgyzstan. L'Europa e la Comunità Internazionale Difronte alle Sfide dello Sviluppo.
Helstosky, C. (2008). Pizza: a global history. Reaktion Books.

Kalnins, A., \& Mayer, K. J. (2004). Franchising, ownership, and experience: A study of pizza restaurant survival. Management Science, 50(12), 1716-1728.

Mattozzi, A. (2015). Inventing the Pizzeria: A History of Pizza Making in Naples. Bloomsbury Publishing.

Mike, B., \& Slocum, J. W. (2003). Changing Culture at Pizza Hut and Yum! Brands, Inc. Organizational Dynamics, 32, 319-330.

Ministero Italiano delle Politiche Agricole, Ambientali e Forestali (MIPAAF) (2015). XV revisione, elenco dei prodotti agroalimentari tradizionali italiani.

Niceforo M., (2019). The art of pizza making in the Neapolitan tradition: a terminological study. The wor (l) ds of neapolitan arts and crafts: cultural and linguistic perspectives.

Sanchez, S. (2008). Frontières alimentaires et mets transfrontaliers: la pizza, questionnement d'un paradoxe. Anthropologie et sociétés, 32(3), 197-212.

Serao, M. (2016), Il ventre di Napoli.

Stanworth, J., Stanworth, C., Watson, A., Purdy, D., \& Healeas, S. (2004). Franchising as a small business growth strategy: a resource-based view of organizational development. International Small Business Journal, 22(6), 539-559.

Taylor, B. (2016). How Domino's Pizza reinvented itself. Harvard Business Review.

Technomic (2017). Pizza: Consumer trend report.

UNESCO, Representative List of the Intangible Cultural Heritage of Humanity, Twelfth session of the Intergovernmental Committee for the Safeguarding of the Intangible Cultural Heritage, December 4-9, 2017. 